\title{
Tunisian Physical Education Student Trainees' Agreement Rate about the Consistency between Initial Training and Integration during the Preparatory Internship for Professional Life
}

\author{
Ghazi Rekik¹, Naila Bali1,2 \\ ${ }^{1}$ High Institute of Sport and Physical Education, Ksar-Saïd, University of Manouba, UMA, Tunis, Tunisia \\ ${ }^{2}$ Tunisian Research Laboratory Sport Performance Optimization, Tunis, Tunisia \\ Email: rekikghazi61@yahoo.fr
}

How to cite this paper: Rekik, G., \& Bali, N. (2017). Tunisian Physical Education Student Trainees' Agreement Rate about the Consistency between Initial Training and Integration during the Preparatory Internship for Professional Life. Creative Education, 8, 373-382.

https://doi.org/10.4236/ce.2017.83029

Received: December 28, 2016

Accepted: March 12, 2017

Published: March 15, 2017

Copyright $\odot 2017$ by authors and Scientific Research Publishing Inc. This work is licensed under the Creative Commons Attribution International License (CC BY 4.0).

http://creativecommons.org/licenses/by/4.0/

\begin{abstract}
This article aims at describing Physical Education Student Trainees' (PEST) agreement rate towards consistency between training and integration during the Preparatory Internship for Professional Life (PIPL). In order to achieve this research, the method used in the quoted investigation is based on an administration of a questionnaire among 116 PEST (average age \pm SD $=21 \pm$ 1.8; sex $=$ males and females) inscribed at one of the four Higher Institutes of Sport and Physical Education in Tunisia. This study resulted in a consensus that there is a lack of consistency between training and integration in the PIPL with a student trainees' global agreement rate on ten equal to $5.09 \pm 0.22$. The results discussed in this article will encourage pushing towards an improvement of the Tunisian physical education initial training devices to prepare well for the future teachers to a successful professional life.
\end{abstract}

\section{Keywords}

Agreement Rate, Physical Education Student Trainees, Initial Training, Preparatory Internship for Professional Life

\section{Introduction}

The initial training has a dual purpose: leading the students to a high enough level of disciplinary training and professionalizing them (Bourdoncle, 1991; Altet, 1994; Lang, 1999).

In Tunisia "The higher institutes of sport and physical education provide for future physical education teachers a dual training: a physical activities training 
(gymnastics, athletics, swimming, handball...) and a biological and human sciences training (anatomy, biomechanics, physiology, psychology, sociology...)”(Bali, 2005).

Thus, these Tunisian training curriculums are supposed to help the future teachers to understand and learn physical activities in a better way, in order to teach them to their future pupils at high school (Bali, 2005).

Therefore, the appropriation, transmission and the acquirement of the necessary professional knowledge for the teaching profession come generally from the actions of this academic curriculum training.

Furthermore, Géronimi (2009) asserts that some pupils' ideas have acquired a different status because these ideas are not gratuitous and they can be a manifestation of an intellectual mechanism much deeper than it appears. For this we can say that the student trainees' agreement rate can be an assessment source of the physical education initial training.

In this context, the achievement period of the preparatory internship for professional life is the right moment to realize our survey in order to evaluate the efficiency of this initial training.

Therefore, the fundamental question of our research is:

Is there a consistency between initial physical education training and integration during the preparatory internship for the professional life?

\section{Methodology}

\subsection{Procedure}

The authorization to conduct this survey is guaranteed by the director of the Tunisian Higher Institute of Sport and Physical Education. The researcher visited the student trainees in their classes in order to present the research objective and to obtain a written approval. This survey rises on an exploratory study wherein we analyzed the student trainees' agreement rate towards the consistency between the initial training and the integration during the preparatory internship for the professional life.

\subsection{Participants}

116 student trainees inscribed at the Higher Institute of Sport and Physical Education of SFAX region in TUNISIA, voluntarily participated to this survey (Table 1). They are registered in the training program as part of the preparatory internship for the professional life during their final year of studies, in which they are supposed to obtain their fundamental license in physical education $(\mathrm{BAC}+3)$. In this internship, the student trainees participated during the entire scholastic year, in a weekly session that consists of 4 hours of teaching. From here comes the term "Physical education student trainees" that was adopted in our survey.

\subsection{Instruments}

The method used in this survey is based on the administration of a questionnaire among 116 student trainees. 
Table 1. The studied sample.

\begin{tabular}{cccc}
\hline \multirow{2}{*}{ Class } & \multicolumn{3}{c}{ The sample's demographic data } \\
\cline { 2 - 4 } & Student trainees' number & Sex & average age \pm ET \\
\hline 3rd year 1 & 13 & Male & \\
3rd year 2 & 16 & Male & \\
3rd year 3 & 15 & Female & Male \\
3rd year 4 & 14 & Male & \\
3rd year 5 & 16 & Female \\
3rd year 6 & 16 & Male \\
3rd year 7 & 11 & Female \\
3rd year 8 & 15 &
\end{tabular}

The questionnaire used is entitled "Q4TE” (Appendix). It is developed and validated by the German researchers Grohmann and Kauffeld (2013).

The simplicity of "Q4TE" makes it a featured choice for this survey wherein every participant is invited to an auto-evaluation on a coded scale from $(0=0 \%$ "Don't agree at all") to (10 = 100\% "Totally agree") about twelve items based on six dimensions:

1) Satisfaction: Here, every student trainee describes his/her agreement rate towards the keepsake and the satisfaction of this initial training.

2) Utility: Here, every student trainee describes his/her agreement rate towards the benefits of the training in the work in the internship.

3) Knowledge: Here, every student trainee describes his/her agreement rate towards the acquired knowledge from the training contents.

4) Application to practice: Here, every student trainee describes his/her agreement rate towards the practical implementation of the training and its contribution to acquiring current professional gestures to be applied at work in the internship.

5) The individual organizational results: Here, every student trainee describes his/her agreement rate towards the satisfaction about the performances' improvement during the internship.

6) The global organizational results: Here, every student trainee describes his/her agreement rate towards the organizational results of the work climate's improvement during the internship

The calculation of the Cronbach alpha coefficient is at least 0.7 for each dimension and for the total of dimensions of the questionnaire. For this reason, it can be said that the "Q4TE" is reliable in the Tunisian context (Table 2).

\subsection{Data Analysis}

For the data analysis, we used: 
Table 2. Reliability analysis concerning all dimensions of the questionnaire used.

\begin{tabular}{ccccc}
\hline Dimensions & $\begin{array}{c}\text { Items' } \\
\text { Number }\end{array}$ & $\begin{array}{c}\text { Variance } \\
\text { score of items }\end{array}$ & S2 & Cronbach alpha \\
\hline Satisfaction & 2 & 15.26 & 23.21 & 0.68 \\
Utility & 2 & 15.26 & 27.84 & 0.90 \\
Knowledge & 2 & 14.24 & 24.14 & 0.82 \\
Application to practice & 2 & 14.46 & 25.97 & 0.88 \\
$\begin{array}{c}\text { Individual organizational results } \\
\text { Global organizational results }\end{array}$ & 2 & 15.98 & 28.83 & 0.89 \\
$\begin{array}{c}\text { Totality of dimensions } \\
\text { Consistency between } \\
\text { (training/PIPL) }\end{array}$ & 2 & 16.16 & 30.16 & 0.92 \\
$\quad$ & 12 & 91.38 & 785.45 & 0.96 \\
$\quad$ & & &
\end{tabular}

- The Excel program used to calculate the Cronbach alpha coefficient for each dimension and for the totality of dimensions of the questionnaire. Here, we based on these 3 steps:

the calculation of:

1. Variance of responses for Items.

2. Sum, median, variance of subjects' responses.

3. Application of the formula.

$$
\alpha=\frac{n}{n-1}\left[1-\left(\frac{\sum_{i=1}^{n} s_{i}^{2}}{s_{x n}^{2}}\right)\right]
$$

Here, $\{\mathrm{n}\}$ is the number of items, $\left\{s_{x n}^{2}\right\}$ is the variance of the total score and $\left\{s_{i}^{2}\right\}$ is the variance of item $i$.

- The independent samples $t$-test used in order to study the significance of the student trainees' agreement rate between both male and female: concerning the consistency between initial training and integration during the preparatory internship for professional life.

- The descriptive statistics used in order to describe the student trainees' agreement rate about all themes of questionnaire. By using this statistical test, we based on two types of indicators: The central tendency indices (Avg = the average) and the dispersion indices ( $\mathrm{SD}=$ the standard error).

\section{Results}

The statistical analysis of the independent samples $t$-test (Table 3 ) shows that there is a small significant difference $(p<0.05)$ between all the student trainees' agreement rate both males and females only concerning the dimension of the acquired knowledge from the training. Despite this small significant difference, the statistical analysis shows that all the student trainees' agreement rates are shared without significant difference concerning the totality of dimensions that reflect the consistency between initial training and integration during the preparatory internship for the professional life. 
Table 3. Signification between all student trainees' agreement rate both males and females: Concerning all dimensions that reflect the consistency between initial training and integration during the PIPL (Preparatory Internship for the Professional Life).

\begin{tabular}{cc}
\hline Dimensions & P:signification \\
\hline Satisfaction & 0.41 \\
Utility & 0.10 \\
Knowledge & $0.02 \neq$ \\
Application to practice & 0.40 \\
Individual organizational results & 0.57 \\
Individual organizational results & 0.06 \\
Totality of dimensions = Consistency between (training/PIPL) & $\mathbf{0 . 1 4 4 7}$ \\
\hline
\end{tabular}

$\neq$ : small significant difference between the all student trainees' agreement rate $(p<0.05)$.

On the other hand, the descriptive statistics' analysis (Avg \pm SD) (Figure 1) shows that all the student trainees were averagely agreeing concerning all of dimensions of the questionnaire.

Thus, concerning the training satisfaction, the female student trainees' (FST) agreement rate is equal to $(4.93 \pm 0.36)$, whereas the agreement rate of the male student trainees $(\mathrm{MST})$ is equal to $(5.31 \pm 0.28)$. Concerning also the training benefits for the trainees' work, the FST agreement rate is equal to $(4.8 \pm 0.42)$, whereas the agreement rate of the MST is equal to $(5.61 \pm 0.29)$. More, concerning acquired knowledge from the training, the FST agreement rate is equal to ( $4.8 \pm 0.39)$, whereas the agreement rate of the MST is equal to (5.87 \pm 0.27$)$.

Moreover, concerning the practical implementation of the training and its contribution to acquiring current professional gestures to be applied at work, the FST agreement rate is equal to $(4.5 \pm 0.38)$, whereas the agreement rate of the MST is equal to $(4.91 \pm 0.3)$. In addition, concerning the satisfaction about the performances' improvement during the internship, the FST agreement rate is equal to $(5 \pm 0.42)$, whereas the agreement rate of the MST is equal to $(5.29 \pm$ 0.31). Finally, concerning the global organizational results of the work climate's improvement during the internship, the FST agreement rate is equal to (4.16 \pm 0.38 ), whereas the agreement rate of the MST is equal to $(5.11 \pm 0.33)$.

In conclusion, concerning the totality of dimensions that reflect the consistency between initial training and integration during the PIPL (Figure 2), the FST global agreement rate is equal to $(4.7 \pm 0.36)$, whereas the global agreement rate of the MST is equal to $(5.35 \pm 0.27)$.

Thus, we can say that all the student trainees were averagely agreeing towards this sort of consistency with a global agreement rate on ten equal to $(5.09 \pm$ 0.22 ). That is why this survey resulted in a consensus that there is a lack of consistency and continuity between physical education initial training and integration during the preparatory internship for the professional life. 


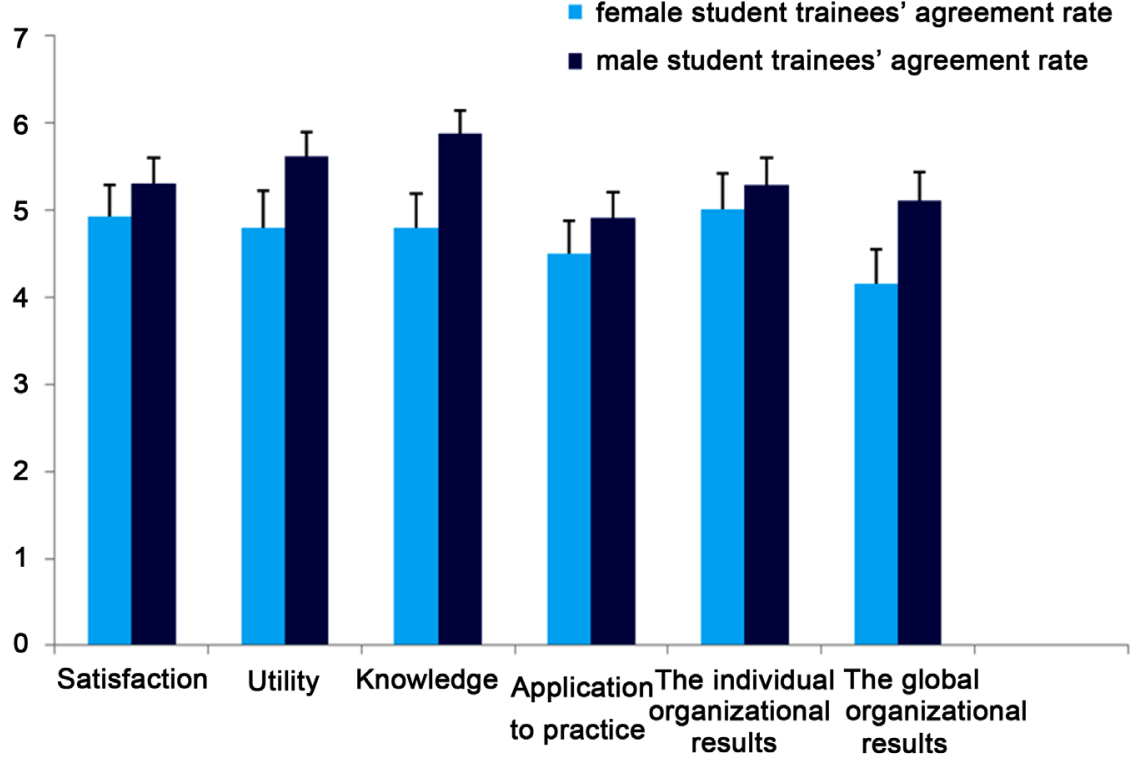

Figure 1. Agreement rate (Avg \pm SD) of all student trainees both males and females: Concerning all dimensions that reflect the consistency between the initial training and the integration during the PIPL (Preparatory Internship for the Professional Life).

Consistency between (training/internship)

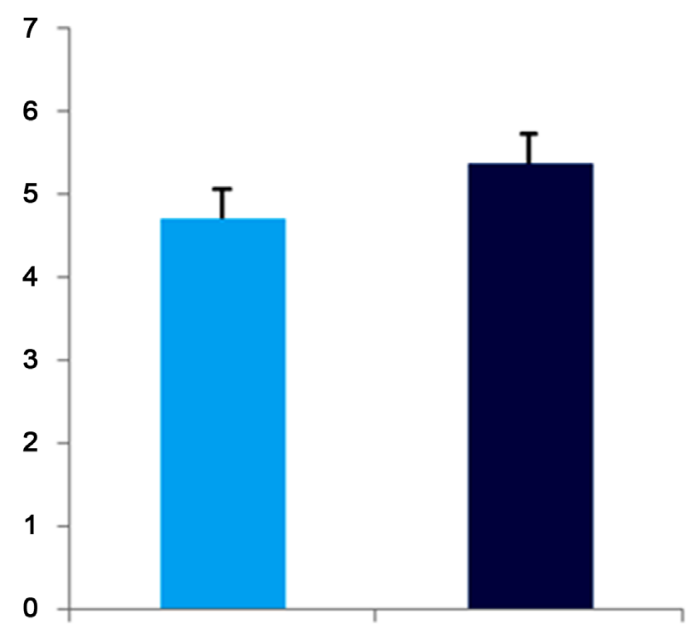

female student trainees agreement rate

male student trainees' agreement rate

Figure 2. Global agreement rate (Avg $\pm \mathrm{SD}$ ) of all student trainees both males and females: Concerning the consistency between the initial training and the integration during the PIPL (Preparatory Internship for the Professional Life).

\section{Discussion}

The first finding of this study shows that the agreement rates of all the student trainees are shared without significant difference between both males and females. In addition, these student trainees were averagely agreeing concerning consistency between initial training and integration during the preparatory internship for the professional life with a global agreement rate on ten equal to $(5.09 \pm 0.22)$. That is why we were able to conclude that there is a lack of consistency and continuity between the initial training and integration during the 
PIPL in the SFAX region in TUNISIA.

In parallel with our study Ria et al. (2010) have mentioned that one of the difficulties which could appear during initial training for the second degree teachers in France was due to the fact of being unable to concretely prepare them for the difficulties of their future profession. More, the finding of this study shows the similar results to those of the study case of "Léa", conducted by Perez (2008) whose has proved within one of the parts of her survey that the consistency and the continuity of the physical education initial training (situation/ lesson/cycle) represent the encountered difficulties during the preparatory internship for the professional life.

Therefore, we can say that the result of our study is in parallel with these studies made to this topic of consistency and continuity between initial training and integration during the professional live (Bali et al., 2014; Bali, 2015). That is why it is necessary to push towards an improvement of our initial training devices in order to prepare well the future teachers to a successful professional life.

The results presented in this study have limitations as a result of the questionnaire administration among the total number of the physical education student trainees inscribed at the Higher Institute of Sport and Physical Education of SFAX region in TUNISIA due to absenteeism (Bali, 2016).

About directions for further research, we will try to integrate a video observation device during the physical education initial training as a support tools for the student trainees during their first teaching experience for a better reflexion on useful teaching/learning situations. This integration of this sort of device will push us to study its effect on the consistency between initial training and integration during the preparatory internship for professional life.

\section{Conclusion}

This study will deepen our knowledge with respect to the consistency between training and integration during the Preparatory Internship for Professional Life in SFAX region in TUNISIA. In this research, we will be able to identify the student trainees' agreement rate towards all the dimensions that are associated with the consistency between initial training and integration during this kind of internship.

However, we recognize that the results presented in this study have limitations as a result of the questionnaire administration among the total number of the physical education student trainees inscribed at the Higher Institute of Sport and Physical Education of SFAX region in TUNISIA due to absenteeism.

In this exercise, we will attempt to establish an overview of the problem related to the effectiveness of the initial training and its consistency with the Preparatory Internship for Professional Life. This sort of evaluation will lead us to question our initial training devices.

In the first category of analysis, our results indicate that the agreement rates of all the student trainees are shared without significant difference between both males and females, concerning: satisfaction, utility, knowledge, application to 
practice, individual and global organizational results. Moreover, these student trainees were averagely agreeing towards the totality of dimensions that reflect the consistency between initial training and integration during the Preparatory Internship for Professional Life with a global agreement rate on ten equal to 5.09 \pm 0.22 .

Identifying student trainees' agreement rates allowed us to target key elements that physical educators can guide their actions in order to make them more effective.

We have successfully demonstrated that there is a lack of consistency and continuity between initial training and integration during the Preparatory Internship for Professional Life. Thus, educators of the Higher Institute of Sport and Physical Education in SFAX region in TUNISIA will be able to push towards an improvement of the initial training devices in order to prepare well for the future teachers to a successful professional life.

Finally, we can add that this study has interesting implications in the field of higher education in general and professional training of physical education future teachers. It must be noted that some student trainees' ideas can be an assessment source of the Physical Education initial training. They are the concern of most interveners in the field of higher education.

\section{References}

Altet, M. (1994). The Professional Training of Teachers: Analysis of Practices and Pedagogical Situations. Paris: Press Universities of France-PUF.

Bali, N. (2005). "Theory and Practice" Articulation in the Training of Tunisian Student Physical Education Teachers. Journal Research and Training, 49, 135-150.

Bali, N. (2015). The Tunisians Cooperative Teachers and Student Teachers' Conceptions about Class Management Skill. Creative Education, 6, 87-99.

https://doi.org/10.4236/ce.2015.61008

Bali, N. (2016). The No-Participation of Students in Physical Education: A Comparative Study of Tunisian Trainee Teachers. Creative Education, 7, 1486-1499. https://doi.org/10.4236/ce.2016.710154

Bali, N., Zayed, W., Hassen, Z., Hermassi, S., Chtara, M., Mrayah, M., \& Desbiens, J. F. (2014). The Conceptions of Integration of Tunisian Physical Education Cooperative Teachers and Student Teachers. Creative Education, 5, 279-289. https://doi.org/10.4236/ce.2014.54037

Bourdoncle, R. (1991). The Professionalization of Teachers: English and American Sociological Analyze. French Review of Pedagogy, 94, 73-92. https://doi.org/10.3406/rfp.1991.1368

Géronimi, A. (2009). How to Use Students' Conceptions to Build Scientific Knowledge. Examples of Sequences on Breathing and Human Reproduction in 3rd Cycle. Professional Memory. Montpellier: IUFM Academy of Montpellier Site Nimes.

Grohmann, A., \& Kauffeld, S. (2013). Evaluating Training Programs: Development and Correlates of the Questionnaire for Professional Training Evaluation. International Journal of Training and Development, 17, 135-155. https://doi.org/10.1111/ijtd.12005

Lang, V. (1999). The Professionalization of Teachers: Meaning and Challenges of Institutional Policy (p. 260). Paris: PUF. 
Perez-Roux, T. (2008). Professionalization and Identity Construction during the Initial Training: The Case of the Second-Degree Teacher Trainees. In R. Wittorski, \& S. Briquet-Duhazé (Eds.), How Teachers Learn Their Profession (pp. 49-80). Paris: The Harmattan.

Ria, L., Serres, G., \& Leblanc, S. (2010). From Video Observation to in Situ Observation of Teachers Working in Difficult Environments: Study of Effects on Teacher Trainees. Schweizerische Zeitschrift für Bildungswissenschaften, 32, 105-120. 


\section{Appendix}

“Q4TE” (Grohmann \& Kauffeld, 2013)

\begin{tabular}{|c|c|c|c|c|c|c|c|c|c|c|c|c|}
\hline \multirow{2}{*}{ Dimensions } & \multirow{2}{*}{ Item } & \multicolumn{11}{|c|}{ Don't agree at all Totally agree } \\
\hline & & $0 \%$ & $10 \%$ & $20 \%$ & $30 \%$ & $40 \%$ & $50 \%$ & $60 \%$ & $70 \%$ & $80 \%$ & $90 \%$ & $100 \%$ \\
\hline \multirow{2}{*}{ 1. satisfaction } & $\begin{array}{l}\text { I will keep the training } \\
\text { in good memory }\end{array}$ & & & & & & & & & & & \\
\hline & $\begin{array}{l}\text { I enjoyed the training } \\
\text { very much }\end{array}$ & & & & & & & & & & & \\
\hline \multirow[b]{2}{*}{ 2. Utility } & $\begin{array}{l}\text { The training is very } \\
\text { beneficial to my work }\end{array}$ & & & & & & & & & & & \\
\hline & $\begin{array}{l}\text { Participation in this kind } \\
\text { of training is very useful } \\
\text { for my job }\end{array}$ & & & & & & & & & & & \\
\hline \multirow[t]{2}{*}{ 3. knowledge } & $\begin{array}{l}\text { After the training, I know } \\
\text { substantially more about the } \\
\text { training contents than before }\end{array}$ & & & & & & & & & & & \\
\hline & $\begin{array}{l}\text { I learned a lot of } \\
\text { new things in the training }\end{array}$ & & & & & & & & & & & \\
\hline \multirow{2}{*}{$\begin{array}{l}\text { 4. Application } \\
\text { to practice }\end{array}$} & $\begin{array}{l}\text { In my everyday work, I often } \\
\text { use the knowledge I gained } \\
\text { in the training }\end{array}$ & & & & & & & & & & & \\
\hline & $\begin{array}{l}\text { I successfully manage to } \\
\text { apply the training contents } \\
\text { in my everyday work }\end{array}$ & & & & & & & & & & & \\
\hline \multirow[b]{2}{*}{$\begin{array}{l}\text { 5. The individual } \\
\text { organizational } \\
\text { results }\end{array}$} & $\begin{array}{l}\text { Since the training, I have been } \\
\text { more content with my work }\end{array}$ & & & & & & & & & & & \\
\hline & $\begin{array}{l}\text { My job performance has } \\
\text { improved through the } \\
\text { application of the } \\
\text { training contents }\end{array}$ & & & & & & & & & & & \\
\hline \multirow{2}{*}{$\begin{array}{l}6 . \text { The global } \\
\text { organizational } \\
\text { results }\end{array}$} & $\begin{array}{l}\text { Overall, it seems to me that } \\
\text { he application of the training } \\
\text { contents has facilitated the } \\
\text { work flow in my company }\end{array}$ & & & & & & & & & & & \\
\hline & $\begin{array}{l}\text { Overall, it seems to me that } \\
\text { the organizational climate has } \\
\text { improved due to the training }\end{array}$ & & & & & & & & & & & \\
\hline
\end{tabular}


Submit or recommend next manuscript to SCIRP and we will provide best service for you:

Accepting pre-submission inquiries through Email, Facebook, LinkedIn, Twitter, etc. A wide selection of journals (inclusive of 9 subjects, more than 200 journals)

Providing 24-hour high-quality service

User-friendly online submission system

Fair and swift peer-review system

Efficient typesetting and proofreading procedure

Display of the result of downloads and visits, as well as the number of cited articles Maximum dissemination of your research work

Submit your manuscript at: http://papersubmission.scirp.org/

Or contact ce@scirp.org 